\title{
15q13.3 microdeletion syndrome
}

INSERM

\section{Source}

INSERM. (1999). Orphanet: an online rare disease and orphan drug data base. 15q13.3

microdeletion syndrome. ORPHA:199318

$15 q 13.3$ microdeletion (microdel15q13.3) syndrome is characterized by a wide spectrum of neurodevelopmental disorders with no or subtle dysmorphic features. 